\title{
Building a predictive machine learning model of gentrification in Sydney
}

\author{
William Thackway, Matthew Ng, Chyi-Lin Lee, Christopher Pettit
}

December 2021

\begin{abstract}
In an era of rapid urbanisation and increasing wealth, gentrification is an urban phenomenon impacting many cities around the world. The ability of policymakers and planners to better understand and address gentrification-induced displacement hinges upon proactive intervention strategies. It is in this context that we build a tree-based machine learning (ML) model to predict neighbourhood change in Sydney. Change, in this context, is proxied by the Socioeconomic Index for Advantage and Disadvantage, in addition to census and other ancillary predictors. Our models predict gentrification from 2011-2016 with a balanced accuracy of 74.7\%. Additionally, the use of an additive explanation tool enables individual prediction explanations and advanced feature contribution analysis. Using the ML model, we predict future gentrification in Sydney up to 2021. The predictions confirm that gentrification is expanding outwards from the city centre. A spill-over effect is predicted to the south, west and north-west of former gentrifying hotspots. The findings are expected to provide policymakers with a tool to better forecast where likely areas of gentrification will occur. This future insight can then inform suitable policy interventions and responses in planning for more equitable cities outcomes, specifically for vulnerable communities impacted by gentrification and neighbourhood change.
\end{abstract}

Keywords: Gentrification, Displacement, Neighbourhood Change, Machine Learning, Housing, Sydney

\section{Introduction}

\subsection{Gentrification and the importance of quantification}

Gentrification refers to the in-migration of upwardly mobile households into lower socioeconomic areas (Pegler et al., 2019), resulting in sweeping changes in the demographic, land-use, and housing affordability of an area, amongst others. In the early 2000's, various policy-oriented studies presented gentrification as a positive outcome for disadvantaged areas that promotes social mixing (Arthurson, 2010). This premise of positive social mixing asserts that the introduction of wealthier residents into disadvantaged areas creates mixed-income communities that have a range of social and economic benefits for poorer residents (Lees, 2008). However, more recent empirical analyses have challenged the social mixing argument (Davidson, 2010; Walks \& Maaranen, 2008) and documented causal evidence of gentrification displacing rental households (Wyly et al., 2010; Martin \& Beck, 2018). The consequences of displacement are well-documented: both on residents, who suffer economic vulnerability, psychosocial stress and educational consequences; and, communities, who lose social diversity and the low-skilled worker base necessary for a functioning economy (Mehdipanah et al., 2017; Pineda, 2017; Atkinson \& Wulff, 2009). 
Gentrification response strategies have primarily focussed on reducing the displacement of lowincome residents from gentrifying communities. Interventions include tenant protection through rent controls and eviction security, controlling ownership and development through taxes and public housing, and community empowerment strategies (Marcuse, 1986). Increasingly, the necessity of quantifying gentrification to tailor harm mitigation strategies is being understood (Easton et al., 2020). Quantifying gentrification at a macro level is recognised as a crucial first step in identifying areas of potential displacement to target policy and community responses (Cohen \& Pettit, 2019). Furthermore, quantitative models help establish objective metrics of gentrification to advocate for policy responses. For example, the development of a housing change index in Minneapolis was lauded for its statistically robust nature because "when you're involved in politics, and competition for scarce resources, the more facts you can provide, the better you are" (Chapple \& Zuk, 2016, pp. 122). Finally, empirical gentrification models raise external awareness and pressure for policymakers to respond. When warning systems and predictions of neighbourhood change are made public, policymakers can no longer feign ignorance (Atkinson \& Wulff, 2009).

Yet, despite the wealth of both qualitative and quantitative studies identifying and investigating the causes of urban gentrification, the application of this understanding to predict future trajectories of neighbourhood change remains limited. Both availability of data and inadequacy of modelling capabilities have imposed major methodological barriers to creating predictive gentrification models within cities (Atkinson \& Wulff, 2009). Resultingly, the majority of studies identify neighbourhood change retrospectively to analyse its causes and consequences. The reactive nature of gentrification studies allows policymakers to employ a "blame the market" tactic that obscures the role of commercial development and public policy in facilitating gentrification (Rigolon \& Nemeth, 2019, pp. 887). Further, the potential for policymakers to mitigate displacement through intervention programs is significantly limited after the pace of change accelerates and gentrification becomes entrenched (Snow et al., 2003). Therefore, early warning systems and predictive empirical models have emerged as essential tools to facilitate proactive intervention policies that prevent rather than react to gentrification pressures (Chapple \& Zuk, 2016).

This paper therefore contributes to the limited predictive gentrification literature by building a tree-based Machine Learning (ML) model to forecast future neighbourhood change in Sydney. Firstly, the paper employs more powerful tree-based models than previous ML gentrification studies (Reades et al., 2019; Palafox \& Monasterio, 2020). The improved performance of boosting methods over random forests enables more accurate and effective neighbourhood change predictions, while also having application in wider urban land use change problems (e.g., Wang \& Lee, 2021). Furthermore, the study incorporates a novel model explanation tool that delineates the influence of each variable on the model output for specific model predictions. This gives greater insight into the indicators of change for specific neighbourhoods than previous studies. Finally, it is the first study to apply ML methods to model and predict gentrification within Sydney, a global city experiencing significant urban growth and housing challenges. The model provides a robust method to quantify the spatial extent of gentrification across the city, while identifying the key socioeconomic and housing indicators. The predictions of future trajectories of Sydney's neighbourhood change provide policymakers with a vital social policy tool in the face of historic housing unaffordability.

\subsection{Sydney as a case study}

Sydney's housing market has historically exhibited the key characteristics that make an area susceptible to gentrification. Firstly, many of Sydney's inner-city areas have previously housed lowincome populations that are vulnerable to displacement (Pegler et al., 2020). Rozelle and Balmain were working-class enclaves close to maritime and heavy industry (Williams, 2010), Glebe, Waterloo and Pyrmont are home to some of Sydney's oldest public housing blocks, and Redfern and Chippendale house a high proportion of Aboriginal and Torres-Strait Islander people (Pegler et al., 2020). Simultaneously, rapidly increasing housing prices over the last three decades have increased 
competition for inner city land. Sydney's median multiple of 11.0 is the third worst of any city globally (Cox-Pavletich, 2020), and inner-city public housing has been systematically dismantled in favour of new private residential stock (Morris, 2018). These conditions have culminated both indirect displacement pressures through rising rental and housing prices, and direct displacement pressures through tenant evictions and land clearance for commercial and government-oriented development (Bounds \& Morris, 2006).

Sydney-based gentrification studies have often taken a case-study approach using media analysis and interviews. Newtown, Pyrmont and Millers Point have been the focus of first wave, second wave, and super-gentrification case studies (Fasche, 2006; Bounds \& Morris, 2006; Morris, 2018). These studies provide rich insights into the manifestation of specific types of neighbourhood change in Sydney. However, they lack the macro scale necessary to develop a comprehensive picture of gentrification across Sydney.

Pegler et al. (2020) developed the first quantitative study of gentrification in Sydney, using a simple analytical framework to identify gentrifying areas between 2006-2016 using census data. 11 of the 13 suburbs identified as gentrifying lay between $5-15 \mathrm{~km}$ from the CBD, which contrasts earlier urban geography theories of gentrification as an inner-city phenomenon. The finding implies that the 'rings of gentrification' will continue to expand outwards from the city centre. Given this finding, the study's condition of an arbitrary $15 \mathrm{~km}$ gentrification limit seems outdated and may understate the true extent of gentrification within Sydney. Furthermore, there is significant room for methodological improvement on the rudimentary statistical methods.

This study extends the range and advances the time period of Pegler et al.'s (2020) study to provide a more comprehensive and updated picture of gentrification within Sydney. Furthermore, it will be the first Sydney-based study to model urban gentrification with a robust, statistically tested model. Through the application of ML methods, this enables predictions of future gentrification which empowers policymakers to make preventative rather than reactive responses to help mitigate gentrification-induced displacement.

\section{Literature Review}

\subsection{Gentrification Policy and the motivation for ML applications}

Acknowledging the significant potential for displacement in upgrading neighbourhoods, government responses to gentrification have been primarily designed to protect housing for low-income residents. Controlling ownership and development is a mitigation strategy that aims to reduce the effect of private investment and development in gentrifying neighbourhoods (Marcuse, 1986). Increasing the supply of public housing ensures a minimum supply of affordable housing, while anti-speculation and luxury taxes target interest-driven ownership (Stienen \& Blumer, 2009). Tenant protection aims to protect tenants from drastic rent increases associated with gentrification through means such as rent subsidies, rent regulation, and rent ceilings (Ghaffari et al., 2017). Finally, community empowerment strategies, such as education and social protection programs, have been proposed to engage residents with local community-level decisions about land use and amenities (Marcuse, 1986).

In cases where governments have intervened in gentrifying areas, studies pre-emptively identifying vulnerable neighbourhoods have been a core element in the design of displacement mitigation strategies. For example, Seattle's Office of Planning \& Community Development (Seattle OPCD) developed the Displacement Risk Index for the Seattle 2035 Comprehensive Equity Plan Analysis (Seattle OPCD, 2016). Areas with higher displacement risk were given lower growth targets, and specific mitigation strategies were designed for each at-risk urban village. The Los Angeles (LA) Innovation Team, created by Mayor Eric Garcetti to promote equitable policy decisions, developed the Los Angeles Index of Neighbourhood Change to inform the prioritisation of pilot areas for their projects 
(Pudlin, 2016). Accessory dwelling units (aka 'granny flats') were the target of new housing supply in vulnerable communities. Similarly, a gentrification index was used by the Local Initiatives Support Corporation (LISC) in Houston to advocate for community housing grants and better rent protection (Winston \& Walker, 2012).

However, it is noted there is a paucity of successful use cases which are supported through the use of predictive gentrification methods. Despite the wealth of gentrification studies identifying and understanding the causes of gentrification, their application in government decision making remains limited. On the one hand, Chapple \& Zuk (2016) cite a lack of trust in the statistical process of neighbourhood change warning systems as their key downfall. Warning systems and displacement vulnerability indexes generally rely heavily on qualitative indicators and rudimentary statistical methods, limiting their predictive accuracy. Among key stakeholders, Pettit \& Green (2016) identified a desire for more robust and empirically tested modelling to underpin policy and planning decisions.

However, it is noted that prevailing quantitative methods used to identify and predict gentrification have been inadequate in capturing the complex spatial and temporal dynamics of neighbourhood change (Royal \& Wortmann, 2015). Discrete time regression models have seen broad applications in modelling displacement, neighbourhood vulnerability, and predicting future gentrification (e.g., Chapple, 2009; Winston \& Walker, 2012). However, the utility of regression to model gentrification is significantly impacted by the correlation of many socioeconomic features (e.g., education, occupation, income). Collinearity can cause model instability and requires additional work to understand feature interactions so as not to confound the model. Regressions also typically make linear assumptions about variable relationships, which limits the complexity of feature interactions within these models. Given the interdependent social and environmental dynamics that drive neighbourhood change, Royal \& Wortmann (2015) conclude that traditional parametric models are inadequate to model gentrification.

More recently, several gentrification studies have employed ML models to capture the complex and dynamic nature of neighbourhood change (e.g., Reades et al., 2019; Palafox \& Ortiz-Monasterio, 2020). ML methods address several of the limitations of traditional parametric models in modelling social change. Firstly, all features can contribute to the model, including those that are correlated or interact with other features (Ogutu et al., 2011). Furthermore, complex interactions between features can be easily accommodated using bagging methods that aggregate a large number of model fits, and the models make no assumptions about the distributions of features (Ogutu et al., 2011). Finally, the scale at which tree-based methods can operate is far larger. ML tree-based methods can tackle both very 'long' (in terms of number of observations) and 'wide' (number of features) datasets (Natekin \& Knoll, 2013). It must be noted that the complexity of ML methods requires greater computational power, and a more complex modelling refinement in order to tune hyperparameters (Hamori et al., 2018). Additionally, ML models have traditionally been black box models where explanatory power of particular inputs are difficult to explain. Despite these drawbacks, ML models have significant strengths in their robustness and flexibility to work with complex spatial-temporal data inputs. This is achieved through their ability to handle complex and correlated feature interactions, while combining many model fits to make one robust model through forest and boosting methods.

Ultimately, the necessity of quality empirical evidence to target proactive gentrification intervention strategies is reflected clearly in the desires of key stakeholders. However, the inadequacy of neighbourhood change warning systems and traditional parametric modelling approaches has significantly limited their uptake. ML methods offer a potential way forward to accommodate the complex dynamics of gentrification and provide a robust, flexible modelling method for use in planning and policy. 


\subsection{Model selection}

While the advantages of employing ML methods compared to traditional parametric methods have been discussed, there are a wide range of ML approaches that can be applied to a regression-based problem.

The most basic and ubiquitous ML method is the Classification and Regression Tree (CART). CART's employ a single decision tree that sequentially splits the sample data into homogenous subgroups, until all observations are assigned a predicted value based on a stopping condition (e.g., max tree depth) (Hayes et al., 2015). While employing a single decision tree is fast to train and can process correlated and non-linear variables, overfitting and variability are risks stemming from its singular approach (Hayes et al., 2015). Ensemble learning presents an alternative to single decision trees that combine multiple tree-based learners to produce one optimal model. Ensemble methods address the instability concerns of CART methods by fitting many trees to bootstrapped samples of the data and aggregating the results to determine the most stable features of the tree (Hayes et al., 2015). There is a general acceptance in the literature that ensemble methods outperform single ML models (Ampomah et al., 2020).

Among the first ensemble learning methods used, Random Forests (RF's) employ random subsets of the feature space for each individual decision tree to reduce the risk of overfitting (Breiman, 2001). The results of a very large number of decision trees are then aggregated to create a forest. They are a versatile and robust method that can model both classification and regression problems with minimal tuning and bias (Breiman, 2001). Boosting machines are another ensemble method that generate a sequence of predictor models, where new base-learners are fitted on the residuals of previous models to improve weak learners (Ogutu et al., 2011). Examples including Gradient Boosted Machines (GBMs), Extreme Gradient Boosting (XGBoost), and Adaptive Boosting (AdaBoost). The primary distinction between boosting methods and RF stems from the order in which new trees are created. Whereas RFs randomly subset the feature space for the selected number of trees and aggregate their outputs, boosting methods consecutively fit new models to improve the prediction of the response variable (Natekin \& Knoll, 2013). Therefore, both forest and boosting methods can accommodate complex relationships and interactions. However, the consecutive nature of boosting methods which cultivates the improvement of weak learners often enables better performance than RFs (Ogutu et al., 2011).

More recently, deep learning (DL) techniques, which simulate neural networks, have been applied a range of vision, speech, and language modelling problems (e.g., Illic et al., 2019; Najafabadi et al., 2015). Here, the artificial intelligence emulating the deep, layered learning process of the brain is better able to extract non-numerical features than other ML techniques (Najafabadi et al., 2015). However, for regression and classification problems, DL methods require far greater complexity in hyperparameter tuning and a huge increase in computing power compared to ensemble methods (Hamori et al., 2018). Furthermore, recent developments in model explanation tools for tree-based methods through packages such as the Local Interpretable Model Explanations (LIME) and SHapley Additive exPlanations (SHAPley) have increased the transparency of ensemble method outputs (Palafox \& Monsterio, 2020). Such methods improve the interpretability of model predictions by expressing them as an additive solution, similar to that of a linear regression. Contrastingly, for DL techniques, there still remains a 'black box' component that reduces their applicability to problems requiring explanation (Hamori et al., 2018).

Considering the competing outcomes of accuracy, stability, efficiency and interpretability, treebased ensemble methods present the most appropriate model choice in the context of a numerical regression problem. They enable more powerful and stable performance than single decision trees, while being quicker to run and allowing for greater model explanation than DL approaches. While several previous gentrification studies have used RFs to predict future gentrification (e.g., Reades et al., Palafox \& Monasterio, 2020), this paper also applies boosting methods which are expected to improve model performance. Furthermore, the use of the emerging advanced model explanation tool SHAPley 
is expected to provide greater transparency and interpretability of model outputs, elevating the model to both a predictive and explanatory tool.

\subsection{ML gentrification studies}

Reades et al. (2019) provided the first and most comprehensive application of a regression-based ML model to predict future urban change, with their predictive RF model of gentrification in London. The first key consideration in constructing a predictive model is how to identify and measure gentrification. Historically, increases in higher income, college-educated, professional, and white residents have all been used as indicators to measure gentrification (Atkinson \& Wulff, 2009). To reconcile these definitional inconsistencies, Reades et al. (2019) combined multiple socioeconomic indicators into a single index using Principal Component Analysis (PCA) (see also: Linton et al., 2017). It must be noted that such an approach is computationally intense and results in a socioeconomic index that is bespoke in nature.

Therefore, where possible, several gentrification studies have instead adopted existing socioeconomic metrics created by government statistic agencies. Examples include the Index of Multiple Deprivation in Britain and the Neighbourhood Change and Gentrification Scale in the US (Sheringham et al., 2017; Narita et al., 2020). In Australia, the Socioeconomic Index for Advantage and Disadvantage (SEIFA) has been used to study the effects of socioeconomic advantage on the housing market, population health etc. (Fong et al., 2019; Hulse \& Reynolds, 2017).

After developing a socioeconomic index to proxy gentrification, Reades et al. (2019) used census demographic and housing variables to predict future neighbourhood change. The RF model was trained using the 2001 input variables to predict the 2011 index and operationalised using the 2011 variables to predict the unknown 2021 index. Areas moving upwards of one standard deviation in socioeconomic rank were classified as gentrifying. The most powerful tuned RF model achieved a moderately high RSquared of 0.699 , and a feature importance plot provided some limited explanatory insights. The paper builds a sound foundation for a predictive gentrification model, devising a sensible method to identify gentrification and providing a comprehensive list of socioeconomic predictor variables. Palafox \& Ortiz-Monasterio (2020) similarly applied both a decision tree and neural network to predict gentrification in Mexico City. They achieved a relatively high accuracy rate, while also applying the Local Interpretation Model-Agnostics Explanation (LIME) tool in Python to provide greater commentary on feature importance.

However, this study extends upon these previous studies through several avenues. Firstly, given the complexity in constructing a socioeconomic index from first principles, using existing statistical indices presents a more practical approach in formulating a multi-dimensional gentrification measurement. Therefore, we will use the SEIFA index in our predictive gentrification model. Considering predictor variables, both studies rely solely on census data, and therefore limit their analysis of neighbourhood change to demographic drivers. Recent studies have identified emerging early indicators of gentrification such as Airbnb and cafes (Wachsmuth \& Weisler, 2018; Glaeser et al., 2017). Hence, incorporating data capturing the housing market, food and leisure amenities, and tourism, may enable a more holistic predictive model. Furthermore, applying boosting methods such as GBM and XGBoost, generally considered more powerful modelling alternatives to RF, are expected to facilitate greater model accuracy. From a methodological perspective, enhancing the performance of ML neighbourhood change models may be applicable to a range of other urban social change processes. Finally, we construct a more sophisticated model interpretation tool than previous studies. In particular, the SHAPley package enables feature contribution analysis for individual model predictions, offering advanced explanations of the drivers of gentrification in different areas. Hence, building upon previous studies, it is possible to create a holistic, robust, and explanatory ML model that improves best practice for predicting future gentrification hotspots. 


\section{Data}

\subsection{Neighbourhood specification}

Given that a predictive model of gentrification predicts change at the neighbourhood level, an appropriate spatial scale must be selected. Given a large degree of the input variables are taken from census data, we are restricted in large part by the construction of census statistical areas. Lauria \& Stout (1995) argue that the smallest available spatial scale is optimal for modelling gentrification. This would translate to the Mesh Block level for census data. However, given that Mesh Blocks typically contain just 30-60 dwellings, this will likely introduce a large degree of noise that may obfuscate wider gentrification trends.

The Statistical Area 1 (SA1) is the next spatial scale, containing 200-800 residents. With over 10,000 SA1's in the greater Sydney region, there is ample data to perform a ML model. Furthermore, while SA1 areas are smaller than the neighbourhoods using in comparable studies (e.g., Reades et al., 2019), they have been employed in several Australian studies measuring neighbourhood outcomes, such as green space (Astell-Burt et al., 2014) and concentration of socioeconomic disadvantage (Pawson et al., 2015). Therefore, the SA1 area was selected as the representation of a neighbourhood in the predictive model.

\subsection{Data Sources}

Table 1 summarises the data sources, input variables, and variable manipulation process. The predictor variables were formed from a combination of census and non-census data sources. All variables were aggregated at the SA1 level. The census variables for the 2011 and 2016 census years were accessed from the ABS website using Table Builder, an open-source tool to aggregate census data at selected spatial scales. These variables span a range of categories used to describe the socioeconomic makeup of a neighbourhood, including demographics, family structure, work, education and migration.

However, the census data does not capture neighbourhood amenities, travel, infrastructure, or housing market indicators. Therefore, we also employed a range of non-census data sources to capture non-socioeconomic changes.

Property data was sourced from the Australian Property Monitors (APM), specifically comprised of residential sales and rental bonds data. Property prices and sales in the prior five years were calculated for houses, units and rentals. Sales of commercial properties were calculated using the NSW Valuer General $(V G)$ dataset, a government dataset that records all residential and commercial property sales within NSW.

The predictor variables also included two emerging gentrification indicators: Airbnb and food and leisure amenities (cafes, yoga studios). Airbnb data was provided by AirDNA, an online web scraping company that collects Airbnb data, while selected food and leisure business numbers were tracked using the Australian Business Register BusinessID data. Finally, new transport infrastructure was captured using the NSW Spatial Services dataset, which logs new ports, train, and bus stations.

The final merged dataset had 10,632 rows and 80 predictor variables. 
Table 1. Summary of data sources, input variables, and variable manipulation process

\begin{tabular}{|c|c|c|c|}
\hline Source & Variable & Levels & Aggregation/Imputation Process \\
\hline \multirow[t]{14}{*}{ Census } & Age & $\begin{array}{l}0-14,15-24,25-34,35-44, \\
45-54,55-64,65+\end{array}$ & \\
\hline & Country of Birth & $\begin{array}{l}\text { Aus/NZ, Europe, UK, Asia, } \\
\text { Americas, Africa }\end{array}$ & \\
\hline & Dwelling Type & $\begin{array}{l}\text { Separate, Apartment, } \\
\text { Terrace, Other }\end{array}$ & \\
\hline & Education Level & $\begin{array}{l}\text { Bachelor/Postgrad, } \\
\text { Diploma/Certificate, Not } \\
\text { Stated }\end{array}$ & \\
\hline & Employment Status & $\begin{array}{l}\text { Employed FT, Employed } \\
\text { PT, Unemployed }\end{array}$ & \\
\hline & Family Composition & $\begin{array}{l}\text { Couple NC, Couple CU15, } \\
\text { Couple NCU15, OPF } \\
\text { CU15, OPF NCU15 }\end{array}$ & \\
\hline & Income & Median Income Weekly & \\
\hline & Industry & $\begin{array}{l}\text { Manu/Construction, } \\
\text { Finance/Tech, } \\
\text { Health/Science, } \\
\text { Accom/Food, } \\
\text { Education, Admin }\end{array}$ & \\
\hline & Marital Status & $\begin{array}{l}\text { Married, Divorced, } \\
\text { Widowed, Never Married }\end{array}$ & \\
\hline & Migration & $\begin{array}{l}\text { Same 5Y, Diff Aus 5Y, Diff } \\
\text { OS 5Y, NS }\end{array}$ & \\
\hline & Occupation & $\begin{array}{l}\text { Manager/Professional, } \\
\text { Labour/Machinery, } \\
\text { Trade, } \\
\text { Cleric/Admin, } \\
\text { Community/Personal } \\
\end{array}$ & \\
\hline & Population & Total Population & \\
\hline & Religion & $\begin{array}{l}\text { Christianity, Islam, } \\
\text { Judaism, Hinduism, } \\
\text { Buddhism, NS }\end{array}$ & \\
\hline & Tenure & $\begin{array}{l}\text { Owned Outright, Owned } \\
\text { Mortgage, Rental }\end{array}$ & \\
\hline \multirow[t]{2}{*}{$\begin{array}{l}\text { Australian } \\
\text { Property } \\
\text { Monitors } \\
\text { (APM) }\end{array}$} & Housing Prices & $\begin{array}{l}\text { House Median, } \\
\text { Unit Median, } \\
\text { Rent Median }\end{array}$ & $\begin{array}{l}\text { - All prices inflated to } 2016 \text { using an inflation } \\
\text { rate of } 2.5 \% \\
\text { - Median price aggregated at the SA1 level } \\
\text { - For SA1 Areas that did not have sufficient data } \\
\text { to reliably estimate the median price ( }<10 \text { sales), } \\
\text { the SA2 median was imputed }\end{array}$ \\
\hline & Housing Supply & $\begin{array}{l}\text { House Supply, } \\
\text { Unit Supply, } \\
\text { Rent Supply }\end{array}$ & $\begin{array}{l}\text { - Number of housing sales within a 5-year period } \\
\text { before the selected period were aggregated at the } \\
\text { SA1 level }\end{array}$ \\
\hline $\begin{array}{l}\text { NSW } \\
\text { Valuer } \\
\text { General }\end{array}$ & $\begin{array}{l}\text { Commercial Property } \\
\text { Sales }\end{array}$ & $\begin{array}{l}\text { Industrial, Office, Shops, } \\
\text { Factory/Warehouse }\end{array}$ & $\begin{array}{l}\text { - Number of commercial property sales within a } \\
\text { 5-year period before the selected period were } \\
\text { aggregated at the SA1 level }\end{array}$ \\
\hline AirDNA & Airbnb & Airbnb Count & - Airbnb count aggregated at the SA1 level \\
\hline $\begin{array}{l}\text { Australian } \\
\text { Business } \\
\text { Register } \\
\text { (ABR) } \\
\end{array}$ & $\begin{array}{l}\text { Food \& Leisure } \\
\text { Businesses }\end{array}$ & $\begin{array}{l}\text { Café/Restaurant, Pub/Bars, } \\
\text { Clubs, Takeaway Foods, } \\
\text { Sport Clubs, Sport Venues, } \\
\text { Health/Fitness }\end{array}$ & $\begin{array}{l}\text { - Number of different food and leisure businesses } \\
\text { aggregated at the SA1 level }\end{array}$ \\
\hline Transport & $\begin{array}{l}\text { New Transport } \\
\text { Infrastructure }\end{array}$ & $\begin{array}{l}\text { New Railway, } \\
\text { New Marina }\end{array}$ & $\begin{array}{l}\text { - Calculated the number of new transport } \\
\text { infrastructure developments within walking } \\
\text { distance for every housing node } \\
\text { - The average of these scores was aggregated at } \\
\text { the SA1 level }\end{array}$ \\
\hline
\end{tabular}




\section{Methodology}

\subsection{SEIFA Index}

The SIEFA index was created by the Australian Bureau of Statistics (ABS) through PCA using 21 variables related to education, occupation, income, rent, employment and household amenities. The full list of variables and further information on how the metric was created is included in Appendix A.

To derive a gentrification classification from this index, the approach used by Reades et al. (2019) was adopted, who argue the importance of considering relative rather than absolute measures of change. Each SA1 area was ranked within Sydney based on their 2011 and 2016 SEIFA score and the change in rank was calculated for each area between 2011 and 2016. Areas moving upwards of one standard deviation of change in rank were classified as 'gentrifying', while areas within one standard deviation of change were classified as 'noise'. One limitation of this approach is the inability of areas with a high starting rank to move substantially further upwards in rank, and thereby be classified as gentrifying. Therefore, this approach is concerned primarily with traditional, 'first-wave' gentrification, rather than later waves of 'super-gentrification'.

\subsection{Model training \& tuning}

The data was partitioned using an 80/20 ratio into a training and a test set. The training and test sets contained 8,506 and 2,126 points respectively. The model was trained using the 2011 input variables to predict the 2016 SEIFA index and operationalised using the 2016 input variables to predict the 2021 SEIFA index. A simple linear regression and several tree-based ML methods were tested: Random Forest (RF), Gradient Boosted Machine (GBM), and Extreme Gradient Boosting (XGBoost).

For each model, a set of parameters specifying how the algorithm should learn needed to be optimised to maximise model performance. For example, tuning the GBM involved the following considerations:

- $\quad$ The minimum number of samples required for a tree to split prevents the model from learning relations which might be highly specific to a specific sample

- A higher number of trees will yield a more complex model, however too many trees can lead to overfitting

- $\quad$ Reducing the number of features considered for each split helps control correlation between trees

- A lower learning rate will make the model robust to specific characteristics of each tree and allow the model to generalise well

Although each ML method requires a different set of hyperparameters to be tuned, the general approach was the same. A complete list of tuned parameters for each model is listed in Appendix B. Parameters were tuned sequentially using k-fold cross-validation. This approach specifies a range of possible values for each parameter, and for each parameter value randomly subsets the training set $k$ times into training and validation sets. For each training set, a new model is fitted, and its performance is evaluated using the corresponding validation set. The model performance of the $k$ model fits is averaged for each parameter value, and the value with the highest average score is selected.

After selecting the optimal set of parameters for each model, the tuned model was re-run using the 2016 inputs variables to predict the unknown 2021 SEIFA index and develop a map of future neighbourhood change. 


\section{Results}

\subsection{Model comparison}

Table 2(a) compares model accuracy in predicting the SEIFA index. However, given that the SEIFA index has a mean value of 1,000 and a low relative standard deviation of 100, all models scored highly on this metric. While it is still possible to differentiate model performance through this metric, a more practical model performance measure is how well it can be used to predict neighbourhood change. Therefore, models were also evaluated on their ability to predict the gentrification flag, defined as SA1 areas experiencing rank change between study periods of greater than one standard deviation (Table 2(b)).

For both metrics, all ML methods, including untuned versions, outperformed the traditional parametric regression. The tuned Gradient Boosted Machine performed most strongly across the board, achieving a SEIFA score $\mathrm{R}^{2}$ of 0.938 and a gentrification balanced accuracy of $74.7 \%$. Notably, the boosting methods materially outperformed the RF model, with the GBM producing a balanced accuracy of more than $1 \%$ higher than the RF. Whereas previous studies have employed RFs to model gentrification (Reades et al., 2019; Palafox \& Monasterio, 2020), these results demonstrate the ability of boosting methods to further improve the accuracy of predictive neighbourhood change models. These findings may have applicability to other fields of urban studies using ML modelling, such population forecasting, property price prediction, and demographic modelling (e.g., Wang \& Lee, 2021; Cesare et al., 2017).

Table 2. Model performance results

a) Predicting SEIFA score

\begin{tabular}{|l|c|c|c|c|}
\hline \multicolumn{4}{|c|}{ SEIFA Score Accuracy } \\
\hline Model & \multicolumn{1}{|c|}{$\mathbf{R}^{\mathbf{2}}$} & \multicolumn{1}{l|}{ MAE } & MSE & MAPE \\
\hline Simple Linear Regression & 0.9127 & 22.77 & 948.57 & 2.26 \\
\hline Random Forest (Default) & 0.9231 & 20.85 & 835.81 & 2.08 \\
\hline Random Forest (Tuned) & 0.9328 & 19.59 & 730.58 & 1.96 \\
\hline Gradient Boosted Machine (Default) & 0.9242 & 20.80 & 824.14 & 2.07 \\
\hline Gradient Boosted Machine (Tuned) & 0.9382 & 18.52 & 671.10 & 1.85 \\
\hline XGBoost (Default) & 0.9202 & 21.29 & 867.03 & 2.13 \\
\hline XGBoost (Tuned) & 0.9357 & 18.87 & 698.13 & 1.88 \\
\hline
\end{tabular}

b) Predicting gentrification flag

\begin{tabular}{|l|c|c|c|}
\hline \multicolumn{4}{|c|}{ Gentrification Flag Accuracy } \\
\hline Model & Accuracy & ROC & F1 \\
\hline Simple Linear Regression & 0.8356 & 0.6701 & 0.4154 \\
\hline Random Forest (Default) & 0.8572 & 0.7132 & 0.4873 \\
\hline Random Forest (Tuned) & 0.8657 & 0.7349 & 0.5210 \\
\hline Gradient Boosted Machine (Default) & 0.8591 & 0.7204 & 0.4975 \\
\hline Gradient Boosted Machine (Tuned) & 0.8732 & 0.7468 & 0.5433 \\
\hline Xgboost (Default) & 0.8648 & 0.7282 & 0.5127 \\
\hline Xgboost (Tuned) & 0.8657 & 0.7379 & 0.5242 \\
\hline
\end{tabular}




\subsection{Mapping neighbourhood change trajectories}

Looking first at the distribution of the SEIFA index throughout Sydney in Figure 1, there are several clear patterns of socioeconomic advantage and disadvantage. Generally, socioeconomic status descends from east to west. Advantaged areas are concentrated along the coastline towards the Eastern Suburbs, North Sydney, and the Northern Beaches. Areas close to the city centre are also predominantly affluent, however there are some anomalous areas of disadvantage in The Rocks and Redfern, where traditional public housing blocks remain despite significant redevelopment pressures (Morris, 2018). Elsewhere, Inner West neighbourhoods are increasingly displaying upwards social mobility, and pockets of advantage are arising towards Sydney's 'secondary CBDs' of Paramatta and Liverpool. Finally, there are several parkland and industrial areas with no population data and therefore no SEIFA score. Examples include Port Botany and Sydney Airport near Botany, Centennial Park near Redfern, and the Royal National Park near Menai.

Comparing 2011 to 2016, some of the clearest visual improvements in socioeconomic status occur in established affluent areas such as the north shore, inner-west, and eastern suburbs. Overall, there is a general flattening of the distribution with less marked instances of intense socioeconomic disadvantage. However, given that the overall socioeconomic conditions of almost all areas have increased, the more interesting analysis lies in comparing the relative change in status between areas over time.

Figure 1. SEIFA scores for Sydney SA1 areas (PRINT IN COLOUR)

a) 2011

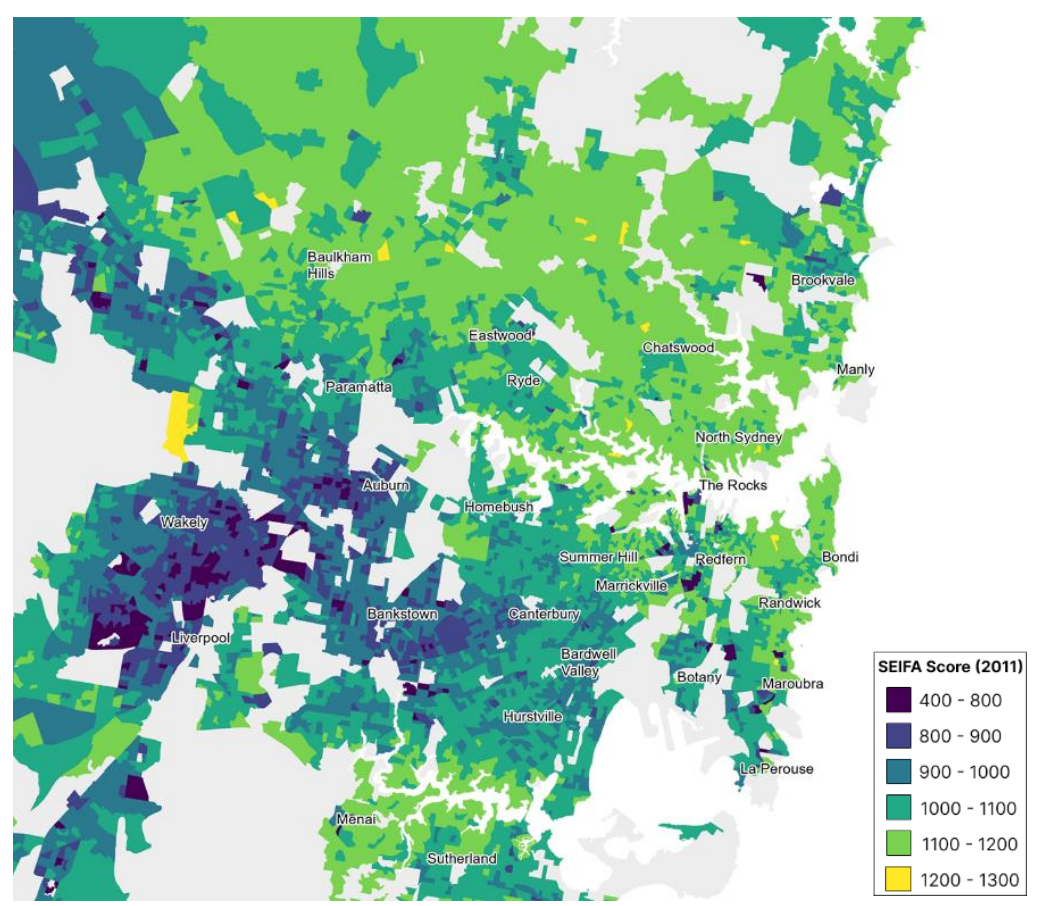

b) 2016

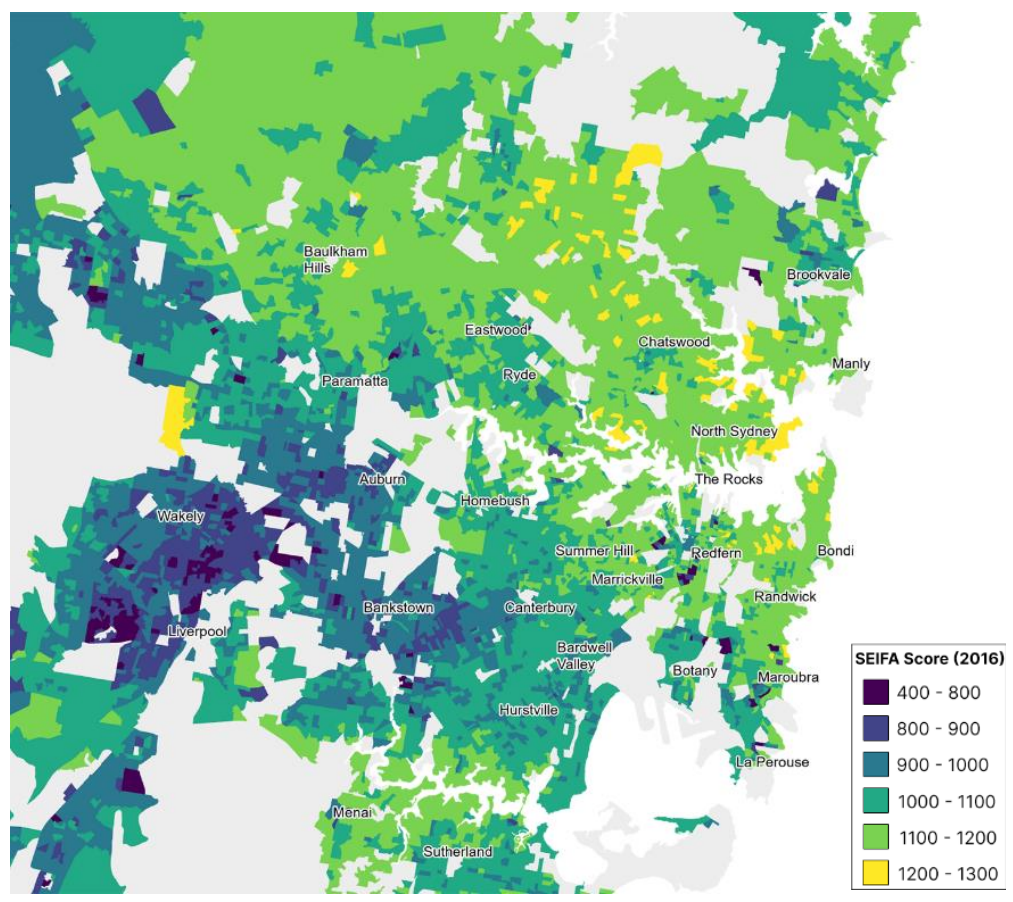

Therefore, following the approach of Reades et al. (2019), a measure of neighbourhood change was constructed by comparing relative changes in socioeconomic ranking between SA1 areas. Each SA1 area was ranked by its SEIFA score, and areas experiencing a rank change between study periods of greater than one standard deviation were classified as undergoing neighbourhood change. Figure 2 illustrates that gentrification between 2011-2016 was heavily concentrated in the inner west suburbs of Redfern, Marrickville, Summer Hill and Canterbury. Randwick and Maroubra in south-eastern Sydney also experienced social uplift, while further west Ryde and Paramatta have emerged as the first gentrifying western Sydney suburbs. 
Pegler et al.'s (2019) study, which mapped gentrification over the same time period identified a similar concentration of socioeconomic uplift in the inner west and south-eastern Sydney. By utilising a finer scale approach applied at the SA1 level, we are able to capture more granular instances of neighbourhood change that may not be picked up at the SA2 level. An example is the hypergentrification of several SA1's in The Rocks, stemming from the redevelopment of several traditional public housing blocks into high-cost inner-city apartments (Bounds \& Morris, 2018). Furthermore, our approach maps both socioeconomic uplift and decline, and we are therefore also able to identify areas undergoing relative urban decay, such as Baulkham Hills, Liverpool and Sutherland. Of far greater consequence however, given the ML methods employed, is the ability to predict future trajectories of change in Sydney.

Figure 2. Standard Deviation of rank change 2011-2016 (+/- 1 not shown) (PRINT IN COLOUR)

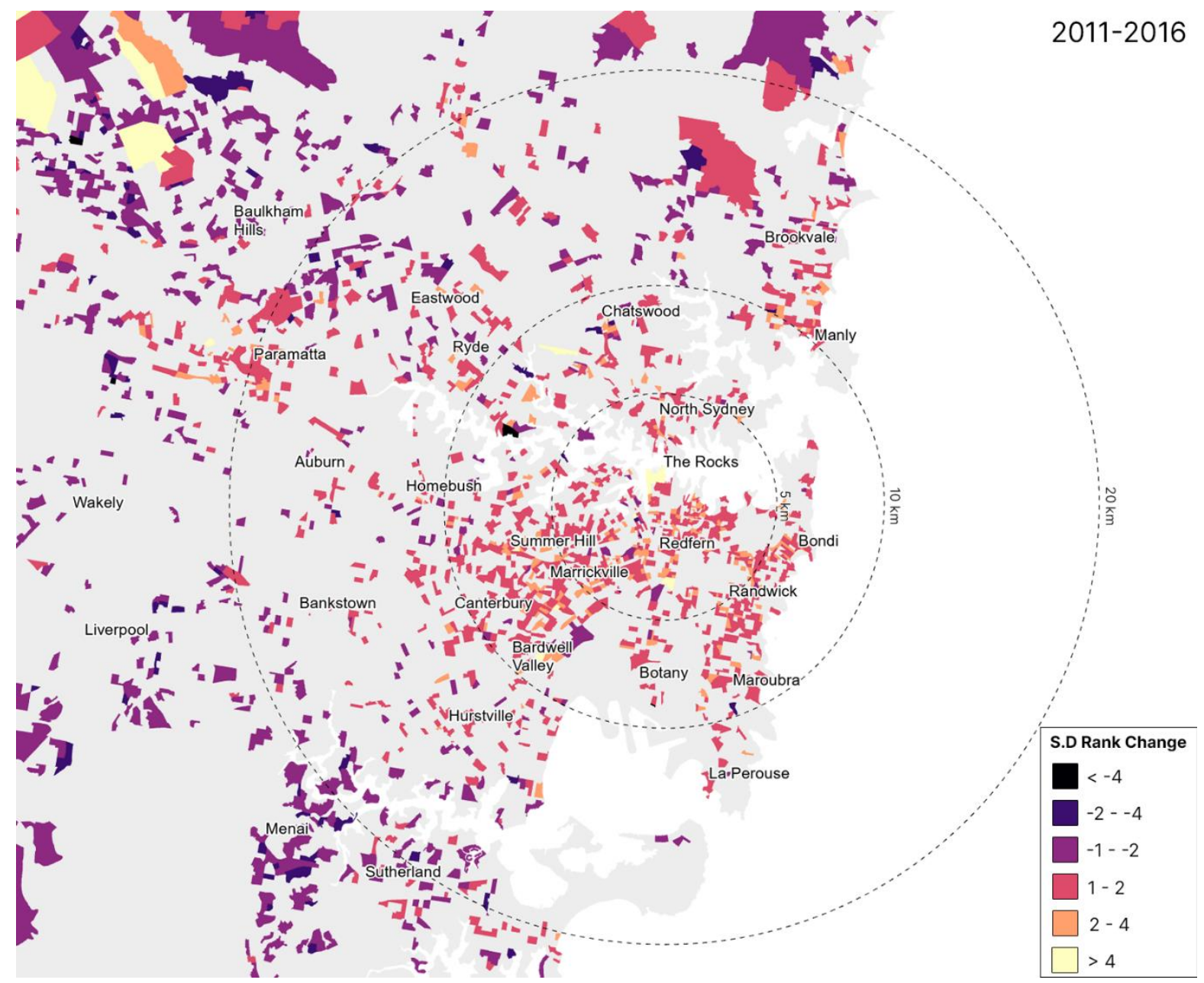

Using the tuned GBM model and the 2016 predictor variables, the unknown 2021 SEIFA index for Sydney SA1 areas was predicted. Applying the same rank change metric, Figure 3 maps predicted neighbourhood change in Sydney between 2016-21. It must be noted that this does not visualise a complete picture of gentrification within Sydney, rather future neighbourhood change from 2016 onwards. Consistent with Pegler et al.'s (2019) findings of the 'rings of gentrification' moving outwards from the city centre, the new predicted hotspots are forming in spill-over zones further west, north and south of previously gentrifying areas. Whereas Pegler et al. (2019) identified gentrifying suburbs in a $5-10 \mathrm{~km}$ ring around the CBD, the gentrification frontier forecasted in our model shows expansion to a $10-20 \mathrm{~km}$ radius around the city centre. 
Figure 3. Standard Deviation of rank change 2016-21 (+/- 1 not shown) (PRINT IN COLOUR)

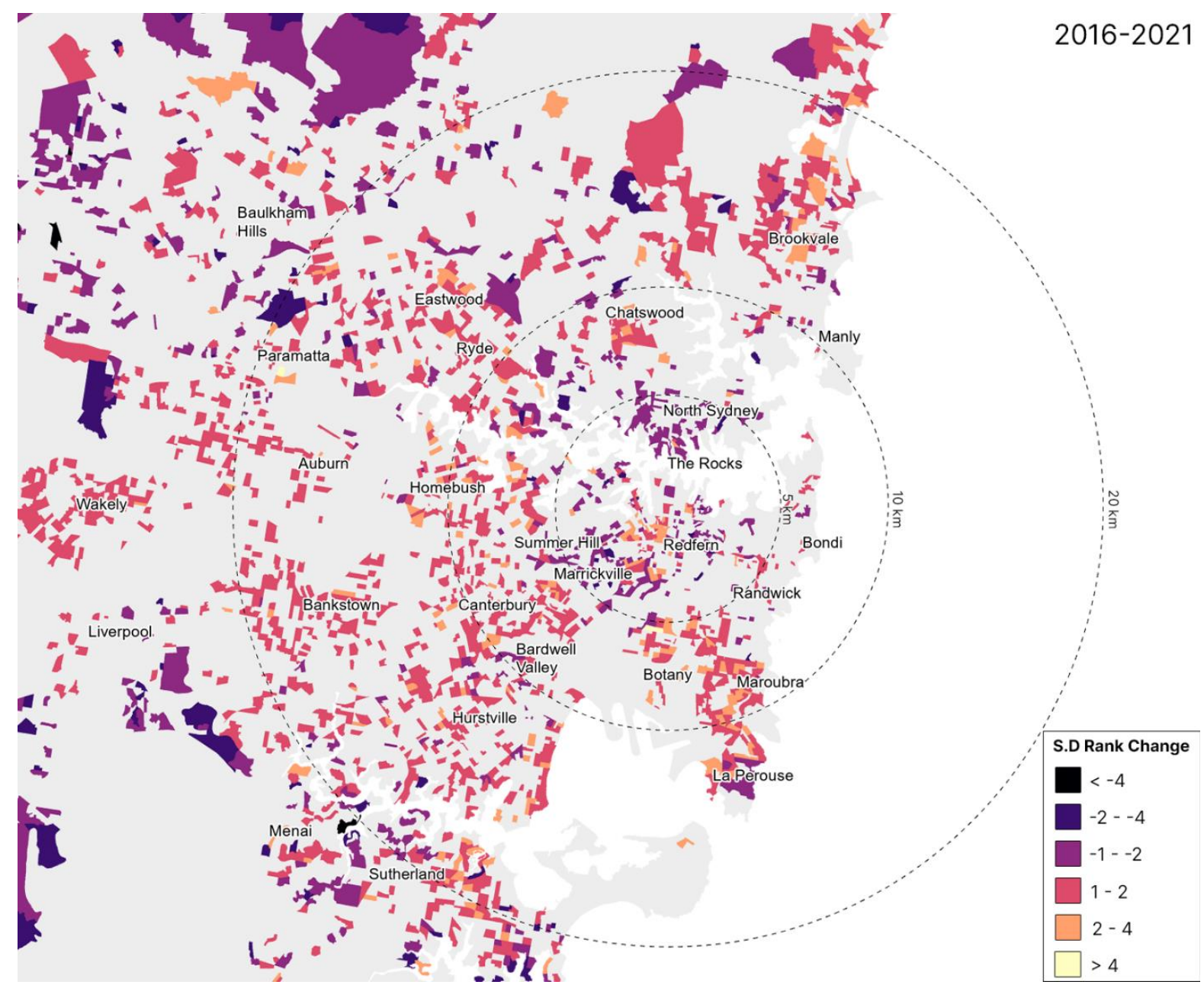

Beyond the inner west, previously high-crime areas of Homebush, Bankstown and Auburn are emerging as hotspot areas. The model results are consistent with Derwin's (2020) findings that from 2011-2020, high crime western Sydney suburbs have experienced capital growth far exceeding Sydney's averages. Derwin (2020) noted that this continues a long-term trend of expansion that was first seen in the inner west and has now expanded to the West and South-West. To the north-west, the wedge of socioeconomic uplift initially recognised in Ryde is forecasted to extend upwards to Eastwood. This area between Paramatta and Ryde has been earmarked as a potential growth area due to its rail connectivity and close proximity to Western Sydney University and the expanding Westmead hospital precinct (Harvey, 2020). To the south, while Menai has mixed results, Sutherland is another predicted hotspot with improved rail connectivity due to a new express service to the CBD, and a major apartment development stimulating new retail shops in the area (Harvey, 2020). Finally, there is a predicted spill-over effect of gentrification south of Randwick towards Botany and Maroubra, and north of Manly towards Brookvale. The areas of Canterbury, Bardwell Valley, and Hurstville display significant change, however this is mixed between gentrifying and declining SA1's.

For a face validation test, Table 3(a) documents house price growth rates of predicted gentrifying suburbs over the past 10 years using APM property sales data. For all suburbs other than Sutherland, the capital growth rates exceed the city-wide median. For Sutherland, where there are also indications of declines in surrounding areas such as Menai, this may indicate that a broader process of neighbourhood change is occurring, not strictly gentrification. Development Approvals (sourced from the NSW Department of Planning, Industry and Environment) have also increased above the Sydney average for all predicted gentrifying suburbs other than Maroubra and Botany (Table 3(b)). In these two 
cases, there were already signs of neighbourhood upgrading between 2011-2016, so a slower relative growth rate in the next 5 years is expected. Overall, the predictions reflect a strong spill-over effect, and the continued expansion of the 'rings of gentrification' outwards from the city centre.

Table 3. Face validation tests of predicted gentrifying suburbs

a) House price growth rates of predicted gentrifying suburbs and Greater Sydney

\begin{tabular}{|l|c|c|c|c|c|}
\hline & \multicolumn{2}{|c|}{$\begin{array}{c}\text { Median House Price } \\
(\$ \mathbf{0 0 0})\end{array}$} & \multicolumn{3}{c|}{10 Year Capital Growth } \\
\hline Suburb & $\mathbf{2 0 1 0}$ & $\mathbf{2 0 2 0}$ & $\begin{array}{c}\text { Gentrifying } \\
\text { Sulburb }\end{array}$ & $\begin{array}{c}\text { Greater } \\
\text { Sydney }\end{array}$ & Difference \\
\hline Auburn & 450 & 795 & $76.7 \%$ & $69.2 \%$ & $7.5 \%$ \\
\hline Bankstown & 495 & 852 & $72.1 \%$ & $69.2 \%$ & $2.9 \%$ \\
\hline Botany & 745 & 1315 & $76.5 \%$ & $69.2 \%$ & $7.3 \%$ \\
\hline Brookvale & 1047 & 2008 & $91.8 \%$ & $69.2 \%$ & $22.6 \%$ \\
\hline Eastwood & 670 & 1230 & $83.6 \%$ & $69.2 \%$ & $14.4 \%$ \\
\hline Maroubra & 920 & 1725 & $87.6 \%$ & $69.2 \%$ & $18.4 \%$ \\
\hline Sutherland & 630 & 1025 & $62.7 \%$ & $69.2 \%$ & $-6.5 \%$ \\
\hline
\end{tabular}

b) Residential development approval growth rates for gentrifying suburbs and Greater Sydney

\begin{tabular}{|l|c|c|c|c|c|}
\hline & $\begin{array}{c}\text { Residential Development } \\
\text { Approvals }\end{array}$ & \multicolumn{3}{c|}{ 5-year growth in DA's } \\
\hline Suburb & $\mathbf{2 0 1 0 - 2 0 1 4}$ & $\mathbf{2 0 1 5}-\mathbf{2 0 1 9}$ & $\begin{array}{c}\text { Gentrifying } \\
\text { Suburb }\end{array}$ & $\begin{array}{c}\text { Greater } \\
\text { Sydney }\end{array}$ & Difference \\
\hline Auburn & 186 & 301 & $61.8 \%$ & $32.6 \%$ & $29.3 \%$ \\
\hline Bankstown & 470 & 662 & $40.9 \%$ & $32.6 \%$ & $8.3 \%$ \\
\hline Botany & 157 & 168 & $7.0 \%$ & $32.6 \%$ & $-25.6 \%$ \\
\hline Brookvale & 1104 & 2133 & $93.2 \%$ & $32.6 \%$ & $60.6 \%$ \\
\hline Eastwood & 1797 & 2634 & $46.6 \%$ & $32.6 \%$ & $14.0 \%$ \\
\hline Maroubra & 883 & 1059 & $19.9 \%$ & $32.6 \%$ & $-12.6 \%$ \\
\hline Sutherland & 1430 & 2346 & $64.1 \%$ & $32.6 \%$ & $31.5 \%$ \\
\hline
\end{tabular}

Interestingly, several affluent areas such as North Sydney and the Inner west document a decline in socioeconomic rank. However, given that the neighbourhood change measure estimates relative change in advantage, a fall in rank likely reflects a stagnation in socioeconomic conditions rather than urban decay. The prediction of no or negative change for Liverpool may also be surprising, given extensive commercial property sales for the 2026 Badgerys Creek airport development (Koziol, 2020). It must be noted that the model utilises 2016 input variables, therefore this information would not have been available at the time of making the prediction. Nonetheless, this illuminates the sensitivity of gentrification to changes in the political and economic landscape. Considering new planning developments alongside this predictive tool will enable more informed responses to future neighbourhood change.

\subsection{Variable Influence on Model Results}

To better understand the effects of the predictor variables, we employed several feature explanation tools. This composed of visualising the overall feature importance, as well as the specific feature contributions for individual neighbourhood predictions. This was done using the SHAPley package, which constructs additive explanations for model results. Firstly, while basic feature 
importance plots display an absolute measure of feature contribution, SHAPley allows for a directional analysis of variable effects (Figure 4).

For example, Figure 4 demonstrates that a higher median personal income is associated with an increase in expected SEIFA score, whereas a higher proportion of residents employed as labourers or machinery operators is associated with a lower expected SEIFA score. While many of the most important features are directly incorporated into socioeconomic status scores (i.e., occupation, income, rent), several demographic features emerge as interesting early indicators of gentrification, such as an increase in the number of young adults or a decline in divorcees and one-parent families. It must be noted that non-census features do not score among the most influential variables, contrary to studies identifying transport, Airbnb and cafes as early gentrification indicators (e.g., Wachsmuth \& Weisler, 2018; Glaeser et al., 2017). However, given that our model predicts socioeconomic status and infers neighbourhood change thereafter, this does not necessarily mean that these factors are insignificant in predicting gentrification. Rather, for the purpose of directly modelling socioeconomic advantage, they are not as impactful as other demographic and income related variables.

Figure 4. Directional feature importance plot of the top 15 most important features

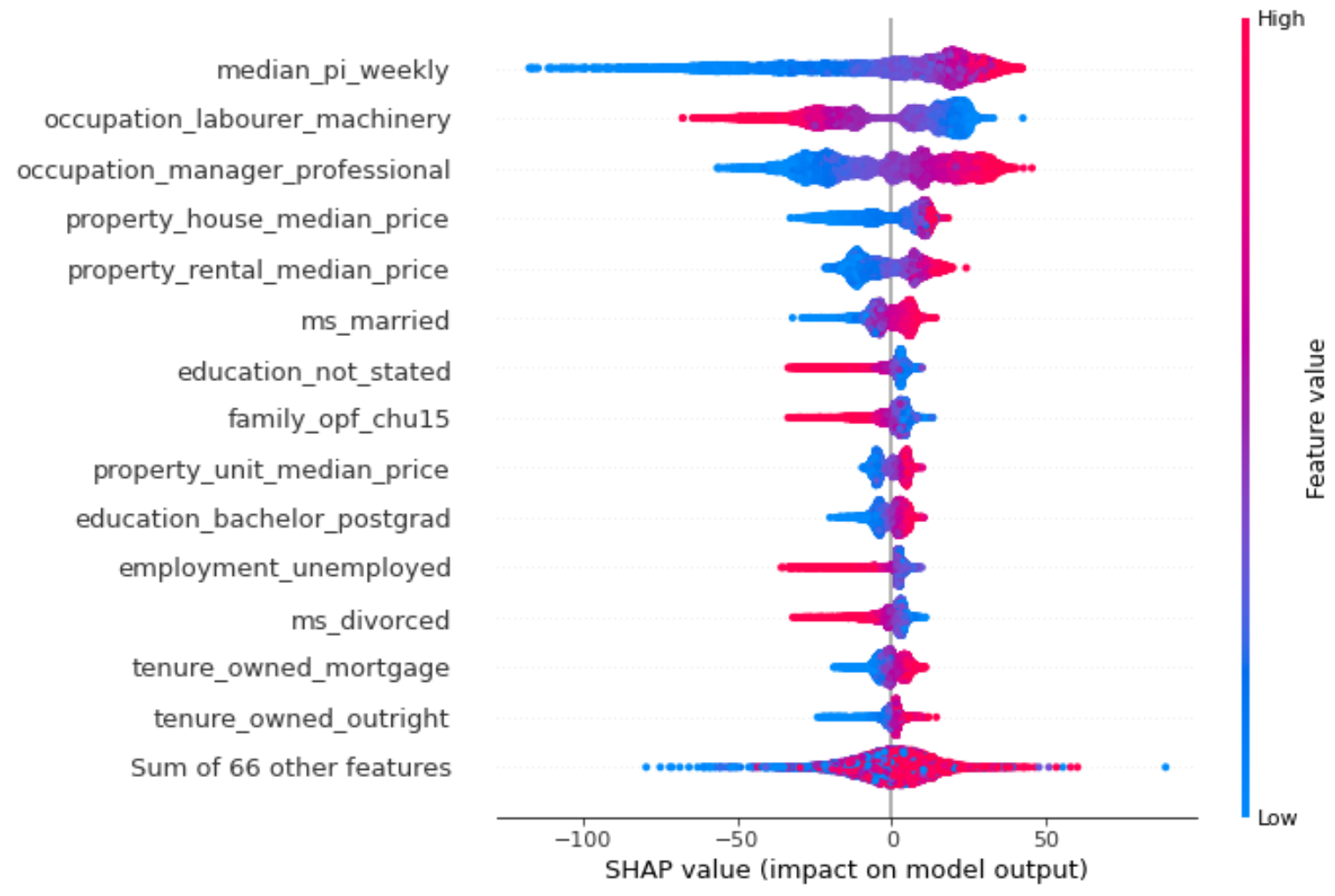

Another unique feature of the SHAPley package is the ability to dissect individual model predictions. This enables targeted analysis of the features flagging neighbourhood change in specific affected neighbourhoods. To demonstrate, Figure 5 compares the model explanation of two gentrifying SA1's in Sutherland and Eastwood. Appendix C provides several further examples of model prediction explanations for gentrifying and declining neighbourhoods.

In Sutherland, where the starting SEIFA score is well below average, demographic changes are the main drivers for a predicted increase in social rank. The median weekly income rising by $\$ 126$ has a net positive effect on the SEIFA score of 16, while an increase in married couples and a decrease in divorcees and one-parent families also contribute to a higher socioeconomic forecast. On the other hand, predicted uplift in Eastwood, where the starting socioeconomic rank is higher, is precipitated by changes to the housing market. Increases in the median house, unit, and rental price between 2011-2016 contribute to a forecast for future neighbourhood change. 
Figure 5. Specific SA1 Prediction Explanations, 2016 - 2021

a) Sutherland (SA1 12802153837): Rank 3,332 - 4,012

2011 Inputs

$384877.611=$ property_house_median_price

$0.167=$ ms_divorced

0.104 = occupation_labourer_machinery

$429.935=$ property_rental_median_price

$0.327=$ ms_married

$0.118=$ dwellings_separate_house

$658=$ median_pi_weekly

0.122 = family_opf_chu15

$0.125=$ education_not_stated

$0.053=$ employment_unemployed

70 other features

2016 SEIFA

$f(x)=980.225$

\section{$-18.5$}

$-13.28$

+12.95

$-11.69$

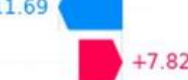

$-4.65$

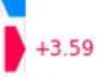

$+2.6$

$-14.03$

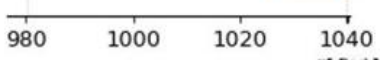

$E[f(X)]=1039.949$
2016 Inputs

021 SEIFA

$f(x)=1030.633$

784 = median_pi_weekly

0.091 = occupation_labourer_machinery

$0.119=$ dwellings_separate_house

$450=$ property_rental_median_price

$0.152=$ ms_divorced

$0.336=$ ms_married

$0.27=$ tenure_owned_mortgage

$0.012=$ education_not_stated

$602654.916=$ property_house_median_price

$0.054=$ family_opf_chu15

70 other features
$+22.05$

$+15.25$

$-14.66$

\section{$-13.98$}

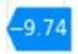

$-8.53$

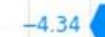

$+4.18$

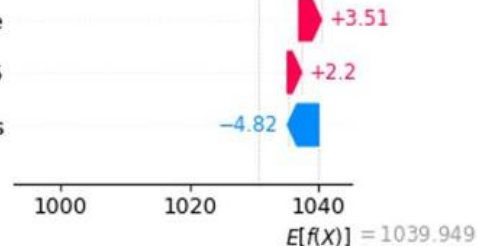

b) Eastwood (SA1 12602149718): Rank 4,456 - 5,155

2011 Inputs

s

85 = median_pi_weekly

2016 SEIFA

$f(x)=1036.405$

0.081 = occupation_labourer_machinery

0.414 = occupation_manager_professional

921956.267 = property_house_median_price

$0.854=$ dwellings_separate_house

$0.062=$ ms_divorced

$0.458=$ education_bachelor_postgrad

$0.589=$ ms_married

$579.847=$ property_rental_median_price

$$
0=\mathrm{cob}_{-}^{3} \mathrm{uk}
$$

70 other features 08
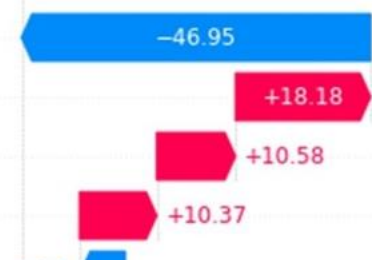

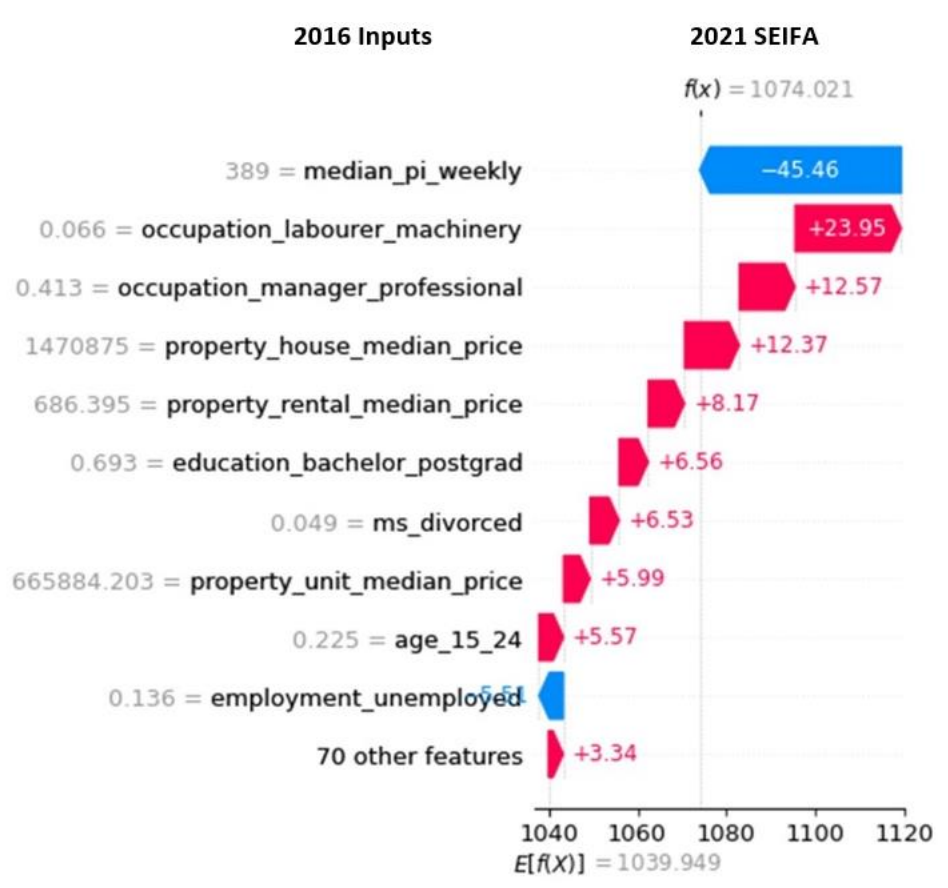

This demonstrates that areas with different socioeconomic makeups can have markedly different drivers of neighbourhood change. Consequently, a 'one-size-fits-all' approach is likely to be ineffective for tackling gentrification. Instead, planners need to consider local demographic and housing contexts when designing intervention strategies. This tool enables a greater level of transparency in understanding neighbourhood change at a granular level to better target gentrification policy and programs. 


\section{Discussion}

The use of neighbourhood change predictions by policymakers and city planners has thus far been limited. A lack of trust in the statistical process of warning systems and the insufficiency of traditional parametric modelling approaches have been the key downfalls. However, more accurate and robust models are more likely to be trusted by policymakers, which will in turn accelerate their uptake for practical implementation in planning and decision making.

This paper presents an accurate and statistically tested method to predict future neighbourhood change using a combination of census and non-census data. Whereas previous neighbourhood warning systems rely upon a set of indicators formed through expert opinions and basic data analysis, our approach applies a robust, iterative framework to model gentrification using a huge range of variables. The application of ML techniques enables non-linear relationships and variable interactions to be accounted and tested using over 10,000 observations. The best performing GBM model achieved an $\mathrm{R}^{2}$ of 0.938 when predicting the SEIFA index, and a balanced accuracy of $74.7 \%$ predicting the gentrification flag. Predicted hotspots are validated against media coverage of gentrification, housing price growth, and development approval data.

This is not to say it is a complete model. The model's performance may be improved by further evaluating the contribution of non-traditional predictors such as Airbnb and cafes to gentrification. Additionally, combining the model predictions with qualitative data such as expert opinions and built environment observations will help to better validate and explain gentrification findings. For practical use in policy and planning spheres, it is fundamental that these quantitative findings are substantiated with appropriate qualitative data. Finally, while the model achieves a reasonably high accuracy, trajectories of neighbourhood change are volatile and can alter dramatically with new developments or policy. Therefore, future predictions will always be limited by the unpredictable dynamics of social and environmental change. However, acknowledging that predictive capabilities will remain imperfect, given the continually unfolding process of gentrification, establishing a statistically tested model that explains how predictions are formed is the best currently available solution.

As such, the model developed in this study is able to deliver accuracy and validation, while providing the lens of objectivity through impartial statistical modelling necessary for policymakers to trust predictions. It provides a vital resource for policymakers and planners to proactively moderate prevention and mitigation strategies before intervention becomes costly and difficult. Too often, gentrification is identified retrospectively, and solutions are implemented after displacement has already occurred. Pettit \& Greene (2016) propose that if city leaders and community groups can get ahead of the curve by predicting future change, they can act to direct neighbourhood change towards more inclusive solutions. Public housing, rent controls, and development taxes aimed at redistributing new wealth to the community are methods to reduce displacement and design more equitable outcomes for changing neighbourhoods.

However, predictive models must also consider their potential use by commercial actors to try to 'game the market' and take advantage of gentrification predictions for personal gain. It is well-known that property investors are always looking for the next 'hidden gem' (e.g., Harvey, 2020), and a robust statistical predictive tool would no doubt be met with enthusiasm by the private market. Nonetheless, neighbourhood change takes time, due to investor caution, political dynamics and lagged housing prices (Kennedy \& Leonard, 2001). Notably, gentrification studies often employ a 10-year study period (e.g., Chapple, 2009; Reades et al., 2019), reflecting the gradual nature of change that takes time to become entrenched. Therefore, if policymakers act upon neighbourhood change early warning signs, it is possible to intervene proactively before the private market actualises gentrification predictions. The vulnerability of urban data science to corporate governance underlines the importance of this tool landing in the hands of planners before private users (Rittenbruch et al., 2021). Crucially, the reaction from planners and policymakers must be swift, or else the price and difficulty of intervening can become an insurmountable barrier. 


\section{Conclusion}

Despite the wealth of neighbourhood change studies retrospectively identifying gentrifying areas, research predicting future hotspots remains limited. On the one hand, traditional parametric models are restricted by their non-collinearity condition and assumption of linear relationships. On the other hand, the uptake of early warning systems using qualitative indicators of neighbourhood change has been curbed by their poor predictive accuracy. In recent years, ML methods have emerged capable of capturing complex, non-linear interactions between variables with high predictive accuracy. While a long-standing limitation of ML models has been their opaqueness, new model explanation tools are increasingly overcoming the 'black-box' component.

In this paper, we apply several tree-based ML tools to predict neighbourhood change in Sydney for the first time. The model contributes both empirical and methodological findings to the gentrification literature. Firstly, it provides the most comprehensive and contemporary view of gentrification within Sydney conducted to date. The projected 2021 gentrification hotspots corroborate Pegler et al.'s (2020) findings of the 'rings of gentrification' expanding outwards from the city centre. Whereas in 2016, gentrifying frontiers were located predominantly in a 5-10km radius around the CBD, this is projected to expand to a $10-20 \mathrm{~km}$ radius by 2021 . New hotspots are forecast to extend from the inner west out to Homebush, Bankstown and Auburn, north-west from Ryde to Eastwood and Baulkham Hills, and south to Sutherland. These predictions are validated against property investor and media articles, housing prices, and development approval data. Additionally, a spill-over effect is predicted from previously gentrifying areas in the northern beaches and south-eastern suburbs. These findings can help policymakers target displacement prevention strategies in affected areas. Furthermore, with the 2021 census data release upcoming, forecasting vulnerable areas for 2026 will provide policymakers with an empirical tool to proactively intervene to design more equitable solutions for vulnerable communities.

Furthermore, the study employs several different ML methods to evaluate the effectiveness of different methods in modelling urban change. The boosting methods markedly outperform the RF, with the GBM balanced accuracy over 1\% higher than RF. This provides a methodological advancement over previous predictive gentrification studies, while having potential applications in modelling other urban change processes. Finally, the model employs an advanced feature explanation tool to improve the transparency of model results. While occupation, income, and rent were the most important socioeconomic indicators, a directional analysis of feature importance illuminated several interesting interactions, such as an increase in divorcees reducing expected socioeconomic status. The tool also enables feature contribution analysis for specific SA1 areas. This allows for targeted analysis by planners and policymakers to develop a tailored response to different gentrifying areas.

In Sydney, as in many global cities where housing unaffordability is rising to unprecedented new levels and competition for urban space is contested, policymakers and planners have often been behind the 8-ball when it comes to gentrification. State-supported housing, rent controls and redistributive taxes are avenues to prevent displacement and share the gains of gentrification with the community. However, the efficacy of these policies relies upon their proactive implementation. By using a predictive tool that forecasts gentrification instead of reacting to it, there is an opportunity for policymakers to shift the balance between public and private recognition of neighbourhood change. If policymakers can act before the private real estate market, it is possible to design more equitable solutions for gentrifying communities. Using the robust and statistically tested model developed in this study, we hope to present part of that solution. 


\section{Acknowledgements}

The authors disclose receipt of the following financial support for the research and authorship of this article: This work has been supported by FrontierSI, a not-for-profit company that exists to deliver major benefits to governments, industry and the community in Australia and New Zealand through the application of spatial information. This research was funded through the Cooperative Research Centre Project -Value Australia.

\section{References}

Ampomah EK, Qin Z and Nyame G (2020), Evaluation of Tree-Based Ensemble Machine Learning Models in Predicting Stock Price Direction of Movement. Information, 11(6), pp. 332, doi: 10.3390/info11060332.

Arthurson K (2010), Operationalising social mix: Spatial scale, lifestyle and stigma as mediating points in resident interaction. Urban Policy and Research, 28, pp. 46-63, doi: https://doi.org/10.1080/08111140903552696.

Astell-Burt T, Feng X, Mavoa S, Badland HM and Giles-Corti B (2014), Do low-income neighbourhoods have the least green space? A cross-sectional study of Australia's most populous cities. BMC Public Health, 292 (2014), doi: https://doi.org/10.1186/1471-2458-14-292.

Atkinson R and Wulff M (2009), Gentrification and displacement: a review of approaches and findings in the literature. AHURI Positioning Paper No. 115, Australian Housing and Urban Research Institute Limited, Melbourne, https://www.ahuri.edu.au/research/position-papers/115.

Bounds M and Morris A (2006), Second wave gentrification in inner-city Sydney. Cities, 23(2), pp. 99-108, doi: https://doi.org/10.1016/j.cities.2005.09.001.

Breiman L (2001), Random forests. Machine Learning, 45(1, pp. :5-32, doi: https://doi.org/10.1023/A:1010933404324.

Cesare N, Grant CE, Nguyen Q, Lee H and Nsoesie E (2017), How well can machine learning predict demographics of social media users. arXiv: Social and Information Networks.

Chapple K (2009), Mapping Susceptibility to Gentrification: The Early Warning Toolkit. Berkeley, CA: Center for Community Innovation.

Chapple K and Zuk M (2016), Forewarned: The Use of Neighborhood Early Warning Systems for Gentrification and Displacement. Cityscape, 18(3), pp. 109-130.

Cohen M and Pettit KLS (2019), Guide to measuring Neighbourhood change to understand and prevent displacement. Washington, DC: Urban Institute.

Cox W and Pavletich H (2020), 16th Annual Demographia International Housing Affordability Survey: 2020. Performance Urban Planning.

Davidson M (2010), Love thy neighbour? Social mixing in London's gentrification frontiers. Environment and Planning A, 42(3), pp. 524-544, doi: https://doi.org/10.1068/a41379.

Derwin J (2020), High levels of crime can't even drive Australian property prices down. In fact, 'risky' suburbs might actually outperform the market. Business Insider Australia, Oct 2020, https://www.businessinsider.com.au/crime-rates-property-prices-trends-gentrification-australia-2020-10.

Easton S, Lees L, Hubbard P and Tate N (2020), Measuring and mapping displacement: The problem of quantification in the battle against gentrification. Urban Studies, 57(2), pp. 286-306. doi:10.1177/0042098019851953.

Fasche M (2006), Creative people and gentrification - "sowing the seeds of demise?" Evidence from Newtown, Sydney. Erdkunde, 60(2), pp. 147-156, doi: 10.3112/erdkunde.2006.02.06.

Fong P, Cruwys T, Haslam C and Haslam SA (2019), Neighbourhood identification buffers the effects of (de-) gentrification and personal socioeconomic position on mental health. Health Place, 57, pp. 247-256, doi: 10.1016/j.healthplace.2019.05.013. 
Ghaffari L, Kliein JL and Baudin WA (2017), Towards a socially acceptable gentrification: A review of strategies and practices against displacement. Wiley, doi: https://doi.org/10.1111/gec3.12355.

Glaeser EL, Kim H and Luca M (2017). Nowcasting the Local Economy: Using Yelp Data to Measure Economic Activity. NBER Working Paper, No. 18-077.

Hamori S, Kawai M, Kume T, Murakami Y and Watanabe C (2018), Ensemble Learning or Deep Learning? Application to Default Risk Analysis. Journal of Risk and Financial Management, 11(1), 12, doi: $10.3390 /$ jrfm11010012.

Harvey R (2020), South and West: Sydney's gentrification hotspots. Property Buyer, 2020, https://www.propertybuyer.com.au/blog/south-west-sydneys-gentrification-hotspots.

Hayes T, Usami S, Jacobucci R and McArdle JJ (2015), Using Classification and Regression Trees (CART) and Random Forests to Analyze Attrition: Results From Two Simulations. Psychol Aging, 30(4), pp. 911929, doi: 10.1037/pag0000046.

Hulse K and Reynolds M (2017), Investification: Financialisation of housing markets and persistence of suburban socio-economic disadvantage. Urban Studies, 55(8), pp. 1655-1671, doi:10.1177/0042098017734995

Illic L, Sawade M and Zarzelli A (2019), Deep mapping gentrification in a large Canadian city using deep learning and Google Street View. PLoS ONE, 14(3): e0212814. https://doi.org/10.1371/journal.pone.0212814.

Kennedy M and Leonard P (2001), Dealing with neighbourhood change: A primer on gentrification and policy choices (Research Discussion Paper 2001). Retrieved from The Brookings Institution Center on Urban and Metropolitan Policy website: https://www.brookings.edu/research/dealing-with-neighborhoodchange-a-primer-on-gentrification-and-policy-choices/.

Koziol M (2020), New York, London, Paris, Badgerys Creek: The developers' gold mine on Sydney's fringe. Sydney Morning Herald, Oct 2020, available at: https://www.smh.com.au/national/nsw/new-yorklondon-paris-badgerys-creek-the-developers-gold-mine-on-sydney-s-fringe-20201021-p567cz.html.

Lauria M and Stout ME (1995), The significance of scale in the analysis of gentrification. College of Urban and Public Affairs (CUPA) Working Papers, 1991-2000:9, University of New Orleans.

Lees L (2008), Gentrification and Social Mixing: Towards an Inclusive Urban Renaissance? Urban Studies, 45 (12), pp. 2249-2270, doi: https://doi.org/10.1177/0042098008097099.

Linton SL, Cooper HL, Kelley ME et al. (2017), Cross-sectional association between ZIP code-level gentrification and homelessness among a large community-based sample of people who inject drugs in 19 US cities. BMJ Open, 7: e013823. doi: 10.1136/bmjopen-2016-013823.

Marcuse P (1986), Gentrification, Abandonment, and Displacement: Connections, Causes, and Policy Responses in New York City. Urban Law Annual; Journal of Urban and Contemporary Law, 28(1), pp. 195-238.

Martin IW and Beck K (2018), Gentrification, Property Tax Limitation, and Displacement. Urban Affairs Review, 54(1), pp. 33-73, doi: https://doi.org/10.1177/1078087416666959.

Mehdipanah R, Marra G, Melis G \& Gelormino E (2017), Urban renewal, gentrification and health equity: a realist perspective. The European Journal of Public Health, 28 (2), 243-248, doi: 10.1093/eurpub/ckx202.

Morris A (2018), 'Super-gentrification' triumphs: gentrification and the displacement of public housing tenants in Sydney’s inner-city. Housing Studies, 34(7), pp. 1071-1088, doi: https://doi.org/10.1080/02673037.2018.1515894.

Najafabadi MN, Vilanustre F, Khoshgoftaar TM, Seliya N, Wald R and Muharemagic E (2015), Deep learning applications and challenges in big data analytics. Journal of Big Data, 2, I, doi: https://doi.org/10.1186/s40537-014-0007-7. 
Narita Z, Knowles K, Fedina L, Oh H, Stickley A, Kelleher I and DeVylder J (2020), Neighbourhood change and psychotic experiences in a general population sample. Schizophrenia Research, 216, pp. 316-321, doi: https://doi.org/10.1016/j.schres.2019.11.036.

Natekin A and Knoll A (2013), Gradient boosting machines, a tutorial. Frontiers in Neurorobotics, 7(21), doi: 10.3389/fnbot.2013.00021.

Ogutu JO, Piepho HP and Schulz-Streeck T (2011), A comparison of random forests, boosting and support vector machines for genomic selection. BMC Proceedings, 5(3), doi: 10.1186/1753-6561-5-S3-S11.

Palafox L and Ortiz-Monasterio (2020), Predicting gentrification in Mexico City using Machine Learning. 2020 International Joint Conference on Neural Networks (IJCNN), Glasgow, UK, pp. 1-5, doi: 10.1109/IJCNN48605.2020.9207685.

Pawson H, Hulse K and Cheshire L (2015), Addressing concentrations of disadvantage in urban Australia. Australian Housing and Urban Research Institute, AHURI Final Report No. 247.

Pegler C, Li H and Pojani D (2020), Gentrification in Australia's largest cities: a bird's-eye view. Australian Planner, 56(8), pp. 1-15, doi: 10.1080/07293682.2020.1775666.

Pettit K and Greene S (2016), What If Cities Used Data to Drive Inclusive Neighborhood Change? Washington, DC: Urban Institute.

Pineda M (2017), The effects of gentrification: inhabitants, education and displacement. University of Massachusetts Boston, Honors College Theses. 28. http://scholarworks.umb.edu/honors_theses/28.

Pudlin A (2016), Los Angeles Index of Neighbourhood Change. City of Los Angeles Open Data, available at: http://geohub.lacity.org/datasets/57e9231c3bd34d44ae49b309b0cb440e_1.

Reades J, De Souza J, Hubbard P (2019), Understanding urban gentrification through machine learning. Urban Studies, 56(5), pp. 922-942, doi: 10.1177/0042098018789054.

Rigolon A and Nemeth J (2019), Towards a socioecological model of gentrification: How people, place and policy shape neighbourhood change. Journal of Urban Affairs, 41(7), pp. 887-909, doi: https://doi.org/10.1080/07352166.2018.1562846.

Rittenbruch M, Foth M, Mitchell P, Chitrakar R, Christensen B and Pettit C (2021), Co-Designing Planning Support Systems in Urban Science: The Questions They Answer and the Questions They Raise. Journal of Urban Technology, doi: 10.1080/10630732.2021.1980319.

Royall RA and Wortmann T (2015), Finding the state space of urban regeneration: modeling gentrification as a probabilistic process using k-means clustering and Markov models. CUPUM 2015 Proceedings, Paper 275.

Seattle Office of Planning \& Community Development (2016), Seattle 2035 Growth and Equity. City of Seattle, available at:

https://www.seattle.gov/Documents/Departments/OPCD/OngoingInitiatives/SeattlesComprehensivePlan/ FinalGrowthandEquityAnalysis.pdf.

Sheringham J, Asaria M, Barratt H, Raine R and Cookson R (2017). Are some areas more equal than others? Socioeconomic inequality in potentially avoidable emergency hospital admissions within English local authority areas. Journal Health Serv Res Policy, 22(2), pp. 83-90. doi: 10.1177/1355819616679198.

Snow C, Pettit KLS and Turner MA (2003), Neighborhood Early Warning Systems: Four Cities' Experience and Implications for the District of Columbia. Washington, DC: Urban Institute Metropolitan Housing and Communities Policy Center.

Stienen A and Blumer D (2009), The equitable regeneration of Berne. In L. Porter, \& K. Shaw (Eds.), Whose urban renaissance (pp. 212-221). London: Routledge.

Wachsmuth D and Weisler A (2018), Airbnb and the rent gap: Gentrification through the sharing economy. Environment and Planning A: Economy and Space, 50 (6), pp. 1147-1170, doi: https://doi.org/10.1177/0308518X18778038.

Walks RA and Maaranen R (2008), Gentrification, social mix, and social polarization: testing the linkages in large Canadian cities. Urban Geography, 29(4), pp. 293-326, doi: 10.2747/0272-3638.29.4.293. 
Wang CY and Lee SJ (2021), Regional Population Forecast and Analysis Based on Machine Learning Strategy. Entropy, 23(6), pp. 256, doi: https://doi.org/10.3390/e23060656.

Williams J (2010), Rozelle. Sydney Journal, 3(1), pp. 35, doi: 10.5130/sj.v3i1.1864.

Winston F and Walker C (2012), Predicting Gentrification in Houston's Low- and Moderate-Income Neighborhoods. LISC, Nov 2012, available at: https://www.lisc.org/media/filer_public/db/5b/db5bb2edf802-443f-a959-

159ae04740da/092717_resource_predicting_gentrification_houstons_low_moderate_income_neighborho ods.pdf.

Wyly E, Newman H, Schafran A and Lee E (2010), Displacing New York. Environment and Planning A: Economy and Space, 42 (11), pp. 2602-2623, doi: https://doi.org/10.1068/a42519.

\section{Appendices}

\section{Appendix A. SEIFA index variables and construction notes}

The variables used to construct the SEIFA index using PCA were:

- $\%$ People aged 15 years and over with no post-school qualifications

- $\%$ Occupied private dwellings with no internet connection

- $\quad \%$ People with stated annual household equivalised income between $\$ 13,000$ and \$20,799 (approx. 2nd and 3rd deciles)

- $\%$ Employed people classified as Labourers

- $\%$ Households paying rent less than $\$ 120$ per week (excluding \$0 per week)

- \% People aged under 70 who have a long-term health condition or disability and need assistance with core activities

- $\%$ Employed people classified as Machinery Operators and Drivers

- $\%$ People (in the labour force) unemployed

- $\%$ One parent families with dependent offspring only

- $\%$ Households renting from Government or Community organisation

- $\%$ Employed people classified as Low Skill Community and Personal Service Workers

- \% Occupied private dwellings requiring one or more extra bedrooms (based on Canadian National Occupancy Standard)

- $\%$ Occupied private dwellings with no car

- $\%$ Occupied private dwellings with four or more bedrooms

- \% People aged 15 years and over at university or other tertiary institution

- $\%$ Households paying mortgage greater than $\$ 2,120$ per month

- \% Households paying rent greater than $\$ 290$ per week

- \% People aged 15 years and over with an advanced diploma or diploma qualification

- $\%$ Employed people classified as Professionals

- $\%$ Occupied private dwellings with a broadband internet connection

- $\%$ People with stated annual household equivalised income greater than \$52,000 (approx 9th and 10th deciles)

Further technical information on how the index was constructed can be found here:

https://www.abs.gov.au/Ausstats/abs@.nsf/7d12b0f6763c78caca257061001cc588/ab37122512b569b 2ca25741700115ea2!OpenDocument. 
Appendix B. Variables tuned for each ML model

Parameters tuned for Random Forest:

- Number of estimators

- Maximum features considered for each split

- Maximum tree depth

- Minimum samples for tree to split

- Minimum samples in a leaf for tree to conduct extra split

- Bootstrap: True or False

Parameters tuned for Gradient Boosted Machine:

- Number of estimators

- Learning Rate

- Subsample of observations selected for each tree

- Maximum features considered for each split

- Maximum tree depth

- Minimum samples for tree to split

- Minimum samples in a leaf for tree to conduct extra split

Parameters tuned for Extreme Gradient Boosting:

- Number of trees

- Learning rate

- Maximum tree depth

- Minimum child weight

- Gamma specifying minimum loss reduction to make a split

- Subsample of observations selected for each tree

- Sample of columns to be considered for each split

- Regularisation parameters: Lambda (L1), Alpha (L2) 
Appendix C. Gentrifying and Declining Neighbourhood Prediction Explanations, 2016 - 2021

a) Auburn (SA1 12501158230): Rank 846 - 1,695

2011 Inputs

361 = median_pi_weekly

0.152 = occupation_manager_professional

$0.278=$ occupation_labourer_machinery

$0.311=$ education_not_stated

655226.781 = property_house_median_price

$0.438=$ ms_married

$367707.669=$ property_unit_median_price

$0.226=$ religion_islam

$0.219=$ tenure_owned_mortgage

$0.047=$ employment_unemployed

70 other features

\section{SEIFA}

$f(x)=891.866$

$-58.51$

$-34.81$

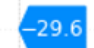

$-11.15$

$+10.41$

$-5.46$

$-5.2$

$-5.15$

$-4.82$

$+4.58$

$-8.38$

000

$E[f(X)]=1039.949$
2016 Inputs

$0.323=$ occupation_labourer_machinery

439 = median_pi_weekly

$0.248=$ occupation_manager_professional

$870000=$ property_house_median_price

0.096 = education_not_stated

0.221 = religion_islam

$0.374=$ ms_married

0.052 = family_opf_chu15

$514.806=$ property_rental_median_price

$0.185=$ tenure_owned_mortgage

70 other features
980

2021 SEIFA

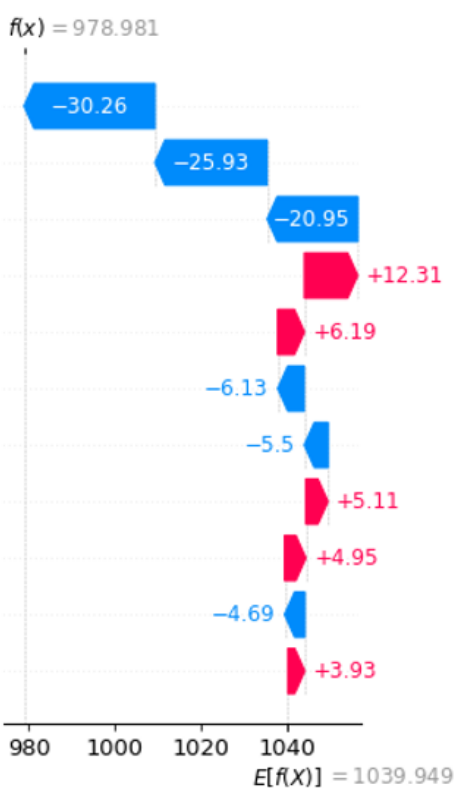

b) Bankstown (SA1 11901135408): Rank 1,152 - 1,824

2011 Inputs

$339=$ median_pi_weekly

0.208 = occupation labourer machinery

$0.136=$ employment_unemployed 0.317 = occupation_manager_professional

$0.261=$ religion_islam

$0.436=$ ms_married

0.19 = family_opf_no_chu15

$0.056=$ ms_divorced

$555710.59=$ property_house_median_price

$475.474=$ property_rental_median_price

70 other features

2016 SEIFA

$f(x)=908.386$

$$
-59.66
$$

$-22.97$

$$
-9.05
$$$$
-8.38
$$$$
-6.3
$$$$
-5.46
$$$$
-5.45
$$$$
+5.26
$$$$
-5.22
$$$$
-3.67
$$$$
-10.65
$$

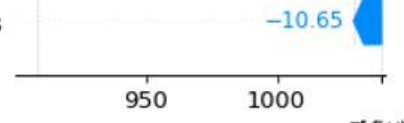

$E[f(X)]=1039.949$
2016 Inputs

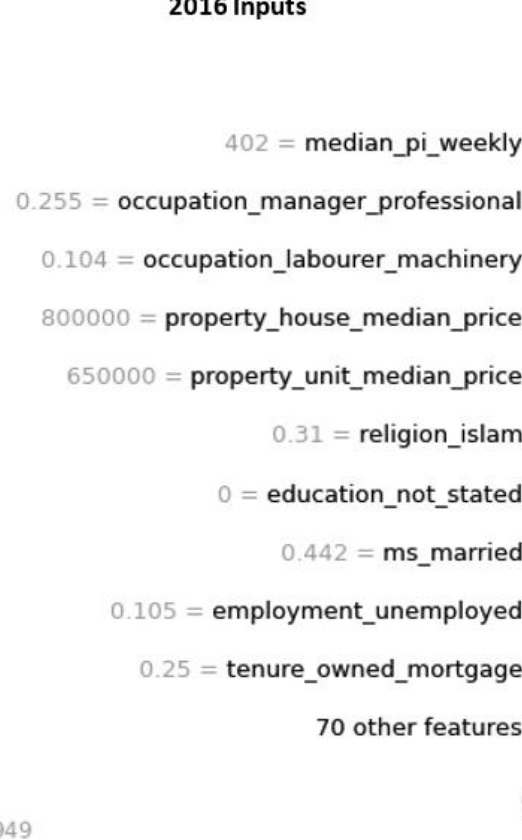

2021 SEIFA

$f(x)=983.035$

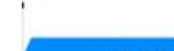

$-45.16$

$+$
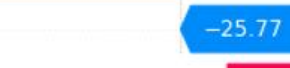
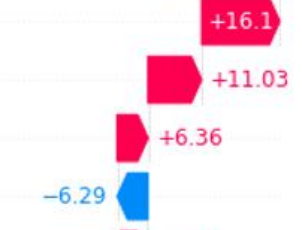

\section{. \\ .}

西

\footnotetext{
r
}

e

es

980 
c) Maroubra (SA1 11802156612): Rank 6,950 - 8,265

2011 Inputs
2016 SEIFA

2016 Inputs

$f(x)=1090.506$
2021 SEIFA
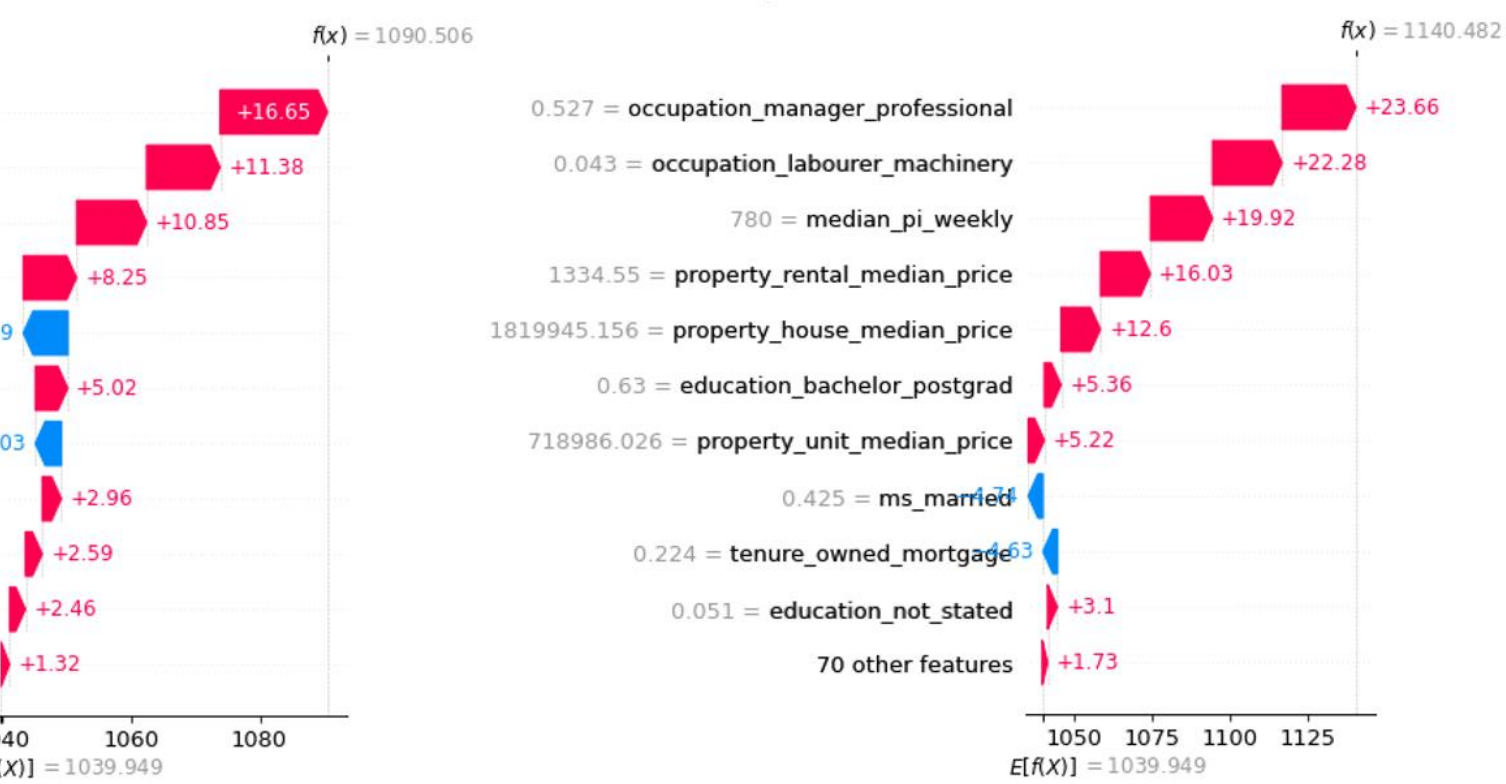

d) Brookvale (SA1 12203142913): Rank 6,870 - 8,075

2011 Inputs

2016 SEIFA

$f(x)=1105.901$
2016 Inputs

2021 SEIFA

$f(x)=1137.31$
$876=$ median_pi_weekly

$0.048=$ occupation_labourer_machinery

$0.463=$ occupation_manager_professional

$1337271.473=$ property_house_median_price

$$
0.379=\text { ms_married }
$$

$531.762=$ property_rental_median_price 77

$0.267=$ tenure_owned_mortgage 3.61

$558682.304=$ property_unit_median_price

0.462 = education_bachelor_postgrad

0.026 = employment_unemployed

70 other featurès 6

$1040 \quad 1060 \quad 1080 \quad 1100$

$E[f(X)]=1039.949$

\section{$+22.54$}

\section{$+17.46$}

$+10.67$

$+3.26$

$+2.75$

$+2.56$

1125 = median_pi_weekly

$+36.23$ 
e) Summer Hill (SA1 12003139633): Rank 6,307 - 5,230

2011 Inputs

2016 SEIFA

$f(x)=1074.181$

792 = median_pi_weekly

$487.071=$ property_rental_median_price

0.432 = occupation_manager_professional

$0.113=$ occupation_labourer_machinery

$734873.382=$ property_house_median_price

$0.476=$ ms_married 5

$0.099=$ religion_buddhism -4.17

$0.044=$ ms_divorced

$0.544=$ education_bachelor_postgrad

0.482 = tenure_owned_mortgage

70 other features $>+1.08$

$\begin{array}{llll}1040 & 1050 & 1060 & 1070 \\ E[f(X)] & =1039.949\end{array}$$$
x)=1074.181
$$

\begin{tabular}{|r|}
\hline+18.55 \\
\hline-12 \\
\hline+11.06 \\
\hline
\end{tabular}

2016 Inputs

2021 SEIFA

$877=$ median_pi_weekly

0.18 = occupation_labourer_machinery

0.412 = occupation_manager_professional

$1260750=$ property_house_median_price

485.678 = property_rental_median_price

$0=$ family_opf_chu15

0.669 = education_bachelor_postgrad

$0.046=$ education_not_stated

$0.079=$ religion_buddhis 2 29

$0.014=$ dwellings_separate_house ${ }^{-3.12}$

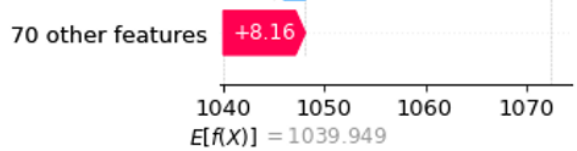

4.04

f) North Sydney (SA1 12104141713): Rank 9,647 - 8,995

2011 Inputs

2016 SEIFA

$f(x)=1156.903$
2016 Inputs

2021 SEIFA

$f(x)=1153.119$
1339 = median_pi_weekly

0.64 = occupation_manager_professional

$0=$ occupation_labourer_machinery

$529857.138=$ property_house_median_price

$487.361=$ property_rental_median_priee 6

0.628 = education bachelor_postgrad

$0.306=$ ms_married 96

0 = family_opf_chu15

$585645.176=$ property_unit_median_price

$+4.89$

$0.077=$ tenure_owned_mortgağ $\bar{e}^{9}$

70 other features

$+6.89$

$1050 \quad 1100 \quad 1150$

$E[f(X)]=1039.949$
$1762=$ median_pi_weekly

$0.62=$ occupation_manager_professional

$0.019=$ occupation_labourer_machinery

$1933150=$ property_house_median_price

$506.139=$ property_rental_median_priee. 6

$0.813=$ education_bachelor_postgrad

$686394.653=$ property_unit_median_price $\mathbf{D}+5.55$

$0.083=$ tenure_owned_mortgáge日

0.127 = family_opf_chu15.7

$0.044=$ ms_divorced

70 other features +4.54

$\begin{array}{lllll}1050 & 1075 & 1100 & 1125 & 1150\end{array}$ $E[f(X)]=1039.949$ $f(x)=1072.546$ 